\title{
Exploiting the antiviral properties of selected phytochemicals from leaf extracts of Spondias mombin (Linn): A computational repurposing approach toward the discovery of potential SARS- CoV-2 inhibitors.
}

Akwasi Boadu ( 2 218069763@stu.ukzn.ac.za )

University of KwaZulu-Natal College of Health Sciences https://orcid.org/0000-0003-3192-2465

Clement Agoni

University of KwaZulu-Natal College of Health Sciences

Rajshekhar Karpoormath

University of KwaZulu-Natal College of Health Sciences

Mahmoud Soliman

University of KwaZulu-Natal College of Health Sciences

Manimbulu Nlooto

University of Limpopo - Polokwane Campus: University of Limpopo

\section{Research Article}

Keywords: Coronavirus, COVID-19, Molecular modeling, SARS-CoV-2 RNA-dependent polymerase, SARS-CoV2, 3C-like main protease, and receptor binding domain of viral S-protein, Spondias mombin

Posted Date: June 21st, 2021

DOI: https://doi.org/10.21203/rs.3.rs-197212/v1

License: (a) (i) This work is licensed under a Creative Commons Attribution 4.0 International License. Read Full License 


\section{Abstract}

Severe Acute Respiratory Syndrome Coronavirus 2 (SARS-CoV-2), a pneumonia-like disease with a pattern of acute respiratory symptoms, remains a major public health concern that is causing tremendous human suffering. There is no approved drug for the direct treatment of the disease, although several vaccines have been approved for use. Exploring medicinal plants and their phytochemicals has emerged as possible therapeutic alternatives since they are affordable and present minimal toxicity effects. This study sought to investigate the potential of the phytochemical compounds isolated from ethanolic leaf extract of Spondias mombin as potential therapeutic agents against SARS-CoV-2. From a select list of bioactive compounds extracted from the leaf of Spondias mombin with known antiviral properties, we identified Geraniin and 2-0Caffeoyl-(+)-allohydroxycitric acid as potential SARS-CoV-2 inhibitors targeting SARS-CoV-2 RNA-dependent polymerase, the receptor-binding domain (RBD) of SARS-CoV-2 viral S-protein and the 3C-like main protease (3CLpro). Analysis of the binding mechanism of these compounds is characterized by the formation of highaffinity intermolecular interactions with respective binding site residues of SARS-CoV-2 RNA-dependent polymerase, 3CLpro, and RBD of viral S-protein, which subsequently contributed to favourable binding affinity. Using the Molecular Mechanics/Poisson-Boltzmann Surface Area (MMPB-SA) approach, Geraniin exhibited a binding free energy ( $\triangle \mathrm{Gbind}$ ) of $-25.87 \mathrm{kcal} / \mathrm{mol}$ and $-21.74 \mathrm{kcal} / \mathrm{mol}$, respectively, whereas $2-0$ Caffeoyl-(+)-allohydroxycitric acid exhibited a $\Delta$ Gbind of $-32 \mathrm{kcal} / \mathrm{mol}$ towards $3 \mathrm{CL}$ pro. Molecular Dynamics (MD) simulations revealed crucial structural changes induced by the identified inhibitors, which possibly interfered with enzyme functions. The molecular insights provided regarding the inhibitory potency of the two phytochemicals warrants further experimental evaluation towards discovering novel SARS-CoV-2 therapeutics.

\subsection{Introduction}

Reported in Wuhan, China, in early December 2019, Severe Acute Respiratory Syndrome Coronavirus 2 (SARS-CoV-2) infection has spread worldwide and was eventually declared a pandemic by the World Health Organisation(WHO) causing the COVID-19 disease with a $2.2 \%$ mortality rate and over 72 million infected persons so far.

SARS-CoV-2 has been classified as a linear single-stranded enveloped Ribonucleic acid (ssRNA) [1] belonging to the family Coronavirinae and genus Betacoronavirus [2]. SARS-CoV-2 is thought to commonly spread via respiratory droplets formed while talking, coughing, and sneezing of an infected patient[3-8]. SARS-CoV-2 could also be transmitted through other body fluids and secretions such as faeces, saliva, urine, semen, and tears[9-11] . Transmission from mother-to-child has also been reported recently[12] . [3-8]. Infection of the virus can also occur through the touching of contaminated surfaces and then subsequently touching one's eyes, nose, and face[13-16]. SARS-CoV-2 infection is characterised by acute respiratory problems, fever, cough, sore throat, loss of taste, loss of smell and myalgia, kidney failure, pneumonia, and death in severe forms of the disease $[7,17]$.

There is currently no approved targeted therapeutics for coronavirus treatment, although several vaccines have been approved for use. Notable vaccines being administered in many parts of the world include; mRNA- 
1273 (Moderna) , BNT162b2 (Pfizer/BioNtech) , ChAdOx1 nCoV-19 (Astrazenac/Oxford), rAd26)/rAd5 (Sputnik V), and Janssen Ad26.COV2.S (Johnson and Johnson)[18-21]. Several targeted coronavirus treatment methods have also been investigated since the breakout of the infection including but not limited to Chloroquine and Hydroxychloroquine, Remdesivir (GS-5734), favipiravir and combination therapy of Lopinavir and ritonavir with the possible addition of interferon-beta[22-28]. The Food and Drug Administration subsequently approved Remdesivir for the treatment of COVID-19 in hospitalized adult and pediatric patients, has demonstrated in vitro activity against SARS-CoV-2 [29-32]. Over 200 clinical trials have been registered so far and currently underway to investigate the potential of these drugs amongst many others[33-35]. Nonetheless, the search for novel treatment options continuous unabated, whereby several therapeutic targets, notably, SAR-CoV-2 receptor-binding domain (RBD), SARS-CoV-2 RNA dependent RNA polymerase (SARS-CoV-2 RdRp), and SARS-CoV-2 3-chymotrypsin-like protease (3CLpro) have been thoroughly explored[36,37]. The availability of the experimentally resolved X-ray crystal structures of these therapeutic targets has further allowed structural exploration of these enzymes towards the design of potential inhibitors [38, 39].

To augment the existing therapeutic options, the focus of several recent reports has included the exploration of the anti-SARS-CoV-2 potential of medicinal plants and their phytochemical extracts. Many of these reports have particularly sought to repurpose natural products with proven antiviral properties towards coronavirus treatment [40-43]. The prominence of medicinal plants for therapeutic purposes is attributed to their affordability, effectiveness, safety, cultural preferences, and ample accessibility and when it is needed [4446]. One of such medicinal plants that have been extensively investigated for antiviral properties is Spondias mombin (S. mombin), [41-43]; however, its therapeutic potential against SARS-CoV-2 remains unexplored.

Spondias mombin (S. mombin), an indigenously tropical African and South American [47] medicinal plant, has been ethnomedicinally used to treat viral infections [48-50] and inflammatory disorders [51-55]. Other reported uses include the treatment of malaria [56-61], fever, sore throat, coughs [57, 62, 63], respiratory tract infections [40], and tuberculosis treatment [64,65]. Available pharmacological evidence indicates that aqueous and alcoholic [52] leaf extracts of $S$. mombin have antiviral, anti-inflammatory,

and antioxidant properties [44, 52,66-72]. Prominent phytochemical constituents of the alcoholic extracts of the leaves of $S$. mombin have included saponins, alkaloids, flavonoids, tannins, oxalates, phytates, cyanogenic glycosides, phenolic derivatives, and vitamins [71, 73]. Of the numerous phytochemicals isolated from the leaf extracts of $S$. mombin, some reportedly possess antiviral activities, as presented in Table $1[49,50,74,75]$.

Table 1: Selected Phytochemicals isolated from ethanolic extracts of the leaves of $S$. mombin with reported antiviral and anti-malarial properties. 


\begin{tabular}{|c|c|c|c|}
\hline No. & $\begin{array}{l}\text { Name of } \\
\text { compound }\end{array}$ & Pharmacological action & reference \\
\hline 1 & Geraniin & $\begin{array}{l}\text { Antiviral properties against Dengue virus type- } 2 \\
\text { (DENV-2), Zika (ZIKV) virus, hepatitis B virus, and } \\
\text { herpes simplex virus type } 1 \text {, Coxsackie B virus. }\end{array}$ & {$[76-84]$} \\
\hline 2 & $\begin{array}{l}\text { 3,5-di-O-galloyl-4- } \\
\text { O-digalloylquinic } \\
\text { acid }\end{array}$ & $\begin{array}{l}\text { Human immunodeficiency virus (HIV) reverse } \\
\text { transcriptase (RT) }\end{array}$ & [85] \\
\hline 3 & $\begin{array}{l}\text { 3-O-digalloyl-4,5- } \\
\text { di-O-galloylquinic } \\
\text { acid }\end{array}$ & $\begin{array}{l}\text { Antiviral activity against Human immunodeficiency } \\
\text { virus (HIV) reverse transcriptase (RT) }\end{array}$ & [85] \\
\hline 4 & $\begin{array}{l}\text { 1,3,4,5-tetra-O- } \\
\text { galloylquinic acid }\end{array}$ & $\begin{array}{l}\text { Antiviral activity against Human immunodeficiency } \\
\text { virus (HIV) reverse transcriptase (RT) }\end{array}$ & [85] \\
\hline 5 & $\begin{array}{l}\text { 2-O-Caffeoyl-(+)- } \\
\text { allohydroxycitric } \\
\text { acid }\end{array}$ & Antiviral activities against Coxsackie B virus & [49] \\
\hline 6 & $\begin{array}{l}6-(8 ' Z, 11 ' Z, 14 ' Z- \\
\text { heptadecatrienyl)- } \\
\text { salicylic acid }\end{array}$ & $\begin{array}{l}\text { Anti-malarial properties against Mycobacterium } \\
\text { fortuitum and chloroquine-sensitive strains of } \\
\text { Plasmodium falciparum }\end{array}$ & {$[86]$} \\
\hline 7 & $\begin{array}{l}\text { 6-(10'Z- } \\
\text { heptadecenyl)- } \\
\text { salicylic acid }\end{array}$ & $\begin{array}{l}\text { Anti-plasmodial properties against Mycobacterium } \\
\text { fortuitum and chloroquine-sensitive strains of } \\
\text { Plasmodium falciparum }\end{array}$ & {$[86]$} \\
\hline
\end{tabular}

This current study seeks to employ computational techniques to investigate the potential of these antiviral leaf extracts of $S$. mombin as inhibitory agents against the SARS-CoV-2 RNA-dependent polymerase [8791], $3 C$-like main protease ( $\left.3 \mathrm{CL}^{\text {pro}}\right)$, and the receptor-binding domain of the viral S-protein of the SARS-CoV2 [92-96]. We also employed in silico methods to perform a thorough assessment of the physicochemical and drug-likeness of any identified phytochemical from the leaf extracts with inhibitory tendencies against the studied SARS-CoV-2 therapeutic targets. We complement our findings with molecular dynamics simulations to unravel essential conformational perturbations that are associated with the potential inhibitory activity of the identified bioactive compounds. Although insilico approaches as employed in this study are inconclusive, the applications of these techniques in our findings could accelerate the discovery of viable anti-SARS-CoV-2 therapeutics and at a low cost.

\subsection{Computational Methodology}

\subsection{System Preparation}

From the Protein Data Bank [97], the X-ray crystal structures of SARS-CoV-2 RNA-dependent polymerase (PDB:7BTF) [98], SARS-CoV-2 3C-like main protease (3CL ${ }^{\text {pro }}$ ) (PDB:6LU7) [99], and the receptor-binding domain of viral S-protein. (PDB:6M17)[100] were retrieved and prepared for molecular docking using UCSF Chimera [101]. To reduce computational cost and resources, DNA, $\mathrm{Zn}^{2+}$, and $\mathrm{Mg}^{2+}$ were all deleted. Using 
UCSF Chimera, hydrogen ions were added before proceeding to perform molecular docking. This was to cater for any missing hydrogen that may not have been present in the retrieved PDB structures. In addition, the definition of at least the polar hydrogens allows the establishment of hydrogen bonds that may be present between the therapeutic targets and the compounds.

\subsection{Retrieval and preparation of investigated phytochemicals}

The two-dimensional (2D) structures of the phytochemicals isolated from ethanolic extracts of the leaves of S. mombin selected for this study were generated using Marvin Sketch [102]. Subsequently, the Avogadro 1.2.0 software [103] was employed to perform energy minimization and optimization of the phytochemicals using the UFF force field and the steepest descent algorithm [100]. Afterward, 3D conformations of the structures were generated and saved as mol2 files for further investigations.

\subsection{Binding pocket identification and molecular docking of modeled structures into SARS-CoV-2 therapeutic targets}

The bound co-crystallized inhibitors were used to map-out the respective binding pockets for the investigated SARS-CoV-2 therapeutic targets. Mapping-out of the binding pocket was performed using the grid box function in AutoDock, Vina [104] whereby respective coordinate which denotes the respective binding pocket of the therapeutic targets were generated. The grid box coordinates for the inhibitor binding site of SARSCoV-2 RNA-dependent RNA polymerase were calculated as; $X=124.119, Y=124.064, Z=133.126$ (center) and $X=22.935, Y=29.805, Z=19.22$ (size). Grid box coordinates for SARS-CoV-2 3CL ${ }^{\text {pro }}$ were calculated as $X=-12.333, Y=13.837, Z=64.250$ (centre), and $X=15.396, Y=14.656, Z=15.085$ (size). The grid box coordinates for the inhibitor binding pocket of the receptor-binding domain (RBD) of viral S-protein were also calculated as $X=28.346, Y=22.296, Z=25.538$ (center), and $X=178.034, Y=122.853, Z=244.886$ (size). Subsequently, molecular docking of the generated bioactive compounds was then carried out using AutoDock Vina. Results of the molecular docking were viewed using the ViewDock function incorporated in UCSF Chimera. The docking results were validated by superimposing generated docked complexes with the retrieved cocrystallized structures of the target SARS-CoV-2 therapeutic targets.

\subsection{In silico exploration of Drug-likeness of hits}

We predicted the physicochemical and pharmacokinetic properties of the studied phytochemicals using SwissADME [105]. These properties provided insights into each of the phytochemicals' absorption, distribution, metabolism, excretion, and toxicity (ADMET). Although these properties could be evaluated using experimental methods, these are usually time-consuming and expensive, hence applying SwissADME. The physicochemical and pharmacokinetic properties of the phytochemicals predicted were also used to ascertain their possible adherence to Lipinski's rules of five, a set of rules widely employed in assessing the drug-likeness chemical compounds[106-108] .

\subsection{Molecular dynamics (MD) simulations}

To reveal the conformational and structural changes that accompany the binding of the identified bioactive compounds to their respective SARS-CoV-2 therapeutic targets, we performed an atomic-scale MD simulation 
using the AMBER $18 \mathrm{GPU}$ with an integrated PMEMD module $[109,110]$. This is because these structural changes could inform their possible inhibitory mechanism of the identified compounds. Any additional cocrystallized molecules such as crystal water were removed from the enzyme structures to minimise computational resources before the beginning of the MD simulation. The ANTECHAMBER module was then used to parameterize the inhibitors, in which atomic partial charges (AM1BCC) were added [111]. The FF14SB AMBER force field was also used to parameterize the enzymes [112]. Protonation of histidine residues was then performed using the pdb4amber script at a constant $\mathrm{pH}(\mathrm{cpH})$ to ensure compatibility of the prepared SARS-CoV-2 therapeutic target models with the LEAP module. Subsequently, the Leap module was then employed to solvate and neutralize the entire prepared systems. The counter ions, $\mathrm{Na}+\mathrm{or} \mathrm{Cl}^{-}$were used to neutralize as systems whereas TIP3P orthorhombic box size of $12 \AA$ of water molecules was added to solvate each system [113]. Topology and coordinate files of the bioactive compounds, SARS-CoV-2 therapeutic targets, and the resultant complexes were then generated and saved. The prepared bound complexes and the unbound enzymes were then subjected to an initial 2000 minimization steps at a restraint potential of $500 \mathrm{kcal} / \mathrm{mol}$ just to minimize the positions of the water and ions. Afterward, a 1000 steps steepest descent minimization with no restraint was performed. The systems were gradually heated from $0 \mathrm{~K}$ to $300 \mathrm{~K}$ for $50 \mathrm{ps}$. After heating, a 500ps equilibration was performed at a constant pressure of $1 \mathrm{bar}$. The pressure was maintained constant using Berendsen barostat [114]. The SHAKE algorithm was employed to constrict all atomic hydrogen bonds, after which a 200ns MD simulation was performed on all simulated models using a $1 \mathrm{fs}$ time step [115]. Coordinates for generated MD trajectories were saved at $1 \mathrm{ps}$ interval. These generated trajectories were further analysed using the PTRJ and CPPTRAJ modules of AMBER [116]. Graphical plots for analysis of the generated trajectories created with the Microcal Origin analytical software [117].

\subsection{Binding Free Energy Calculations}

Computer-based binding free energies of the identified phytochemicals were calculated using the Molecular Mechanics/Poisson-Boltzmann Surface Area (MMPB-SA) techniques $[118,119]$. MMPB-SA as a reliable technique is used to evaluate docking poses, determine structural stability, and predict binding affinities and hotspots. Also, MMPB-SA can be employed to analyse the energy contributions from individual residues through energy decomposition analysis. In this report, the binding free energies of the identified inhibitors were calculated using some known inhibitors of the respective targets as a control. This allowed for an assessment of the inhibitory potential of the identified compounds. MMPB-SA has been applied widely in protein-ligand interactions with proven reliability over the years. The binding free energy (DGbind) was determined by the equations:

DGbind $=$ Gcomplex $-($ Greceptor + Gligand $)$

$D G_{\text {bind }}=D H-T D S=D E_{M M}+D G_{\text {sol }}-T D S$ (2)

in which

$D E_{M M}=D E_{i n t}+D E_{v d w}+D E_{\text {elec }}$ 
$\mathrm{G}_{\mathrm{sol}}=\mathrm{G}_{\mathrm{PB}}+\mathrm{G}_{\mathrm{SA}}$

$\mathrm{G}_{\text {non_polar }}=\mathrm{gSASA}+\beta$

where $\Delta \mathrm{E}_{\mathrm{MM}}, \Delta \mathrm{G}_{\mathrm{sol}}$, and $-\mathrm{T} \Delta \mathrm{S}$ are the changes in the gas phase molecular mechanics (MM) energy, solvation free energy, and conformational entropy upon ligand binding respectively. $D E_{M M}$ is also the sum of the internal energy terms $D_{\text {int }}$ (bond, angle, and torsion), van der Waals ( $\left.D E_{v d w}\right)$ and the non-bonded electrostatic energy component $\left(D E_{\text {elec }}\right)$. The solvation free energy, $G_{\text {sol }}$, on the other hand, is a summation of the electrostatic solvation energy $\Delta \mathrm{G}_{\mathrm{PB}}$ (polar contribution) and the nonpolar contribution $\Delta \mathrm{G}_{\mathrm{SA}}$ between the solute and the continuum solvent. $\mathrm{G}_{S A}$ is calculated from the solvent assessable surface area (SASA), obtained utilizing a $1.4 \mathrm{~A}^{\circ}$ water probe radius whereas the polar contribution is calculated using $\mathrm{PB} . \gamma$ and $\beta$ represented empirical constants for $0.00542 \mathrm{kcal} /\left(\mathrm{mol} \cdot \AA^{2}\right)$ and $0.92 \mathrm{kcal} /\left(\mathrm{mol} \cdot \AA^{2}\right)$, respectively.

\subsection{Results And Discussion}

3.1 Investigation of the possible binding mechanisms of antiviral phytochemical ethanolic leaf extract of $S$. mombin against SARS-CoV-2 therapeutic targets

\subsubsection{Molecular Docking of the antiviral phytochemical ethanolic leaf extracts of S. mombin with SARS-CoV-2 RNA dependent RNA polymerase, SARS-CoV-2 $3 C^{\text {pro }}$ and RBD of viral S-protein}

To explore the inhibitory potential of the phytochemical compounds from ethanolic leaf extract of $S$. mombin against SARS-CoV-2 therapeutic targets, molecular docking was performed. The docking scores which gave insights into the possible binding affinity of the compounds against the studied targets were calculated as presented in Table 2.

Table 2: Docking scores of selected phytochemical compounds against SARS-CoV-2 RdRp, $3 C L^{\text {pro }}$ and RBD of viral S-protein. 


\begin{tabular}{|llll|}
\hline $\begin{array}{l}\text { The reported antiviral and } \\
\text { antioxidant bioactive compound } \\
\text { from Spondias mombin }\end{array}$ & $\begin{array}{l}\text { SARS-CoV-2 } \\
\text { RNA-dependent } \\
\text { RNA polymerase } \\
\text { (kcal/mol) }\end{array}$ & $\begin{array}{l}\text { Receptor binding } \\
\text { domain (RBD) of } \\
\text { viral S-protein } \\
\text { (kcal/mol) }\end{array}$ & $\begin{array}{l}\text { SARS-CoV-2 } \\
\text { 3C-like } \\
\text { Main } \\
\text { protease } \\
\text { (kcal/mol) }\end{array}$ \\
\hline Geraniin & -10.4 & -7.3 & 31.2 \\
\hline $\begin{array}{l}\text { 6-(8'Z,11'Z,14'Z- } \\
\text { heptadecatrienyl)-salicylic acid }\end{array}$ & -5.1 & -4.9 & -5.2 \\
\hline $\begin{array}{l}\text { 2-O-Caffeoyl-(+)- } \\
\text { allohydroxycitric acid }\end{array}$ & -6.8 & -5.6 & -5.6 \\
\hline $\begin{array}{l}\text { 3,5-di-O-galloyl-4-O- } \\
\text { digalloylquinic acid }\end{array}$ & -9.0 & -7.2 & -0.5 \\
\hline $\begin{array}{l}\text { 3,4-di-O-galloyl-5-O- } \\
\text { digalloylquinic acid }\end{array}$ & -8.3 & -6.0 & 1.1 \\
\hline $\begin{array}{l}\text { 3-O-digalloyl-4,5-di-O- } \\
\text { galloylquinic acid }\end{array}$ & 9.1 & -6.4 & -3.9 \\
\hline $\begin{array}{l}\text { Remdesivir } \\
\text { Ritonavir }\end{array}$ & -8.2 & -- & -- \\
\hline
\end{tabular}

Docking scores allow for the determination of the most favourable binding orientation of a compound within a given binding pocket. A favourable binding orientation, of a ligand within a given pocket consequentially informs the nature of binding interaction and hence influences overall binding affinity [120]. The lower the docking score, the more favourable the corresponding binding orientation [120]. As shown in Table 2, molecular docking of all the studied compounds at the active site of SARS-CoV-2, revealed that Geraniin exhibited the most favourable binding orientation at the inhibitor binding sites of both SARS-CoV-2 RdRp and the RBD of viral S-protein with the highest docking score of $-10.4 \mathrm{kcal} / \mathrm{mol}$ and $-7.3 \mathrm{kcal} / \mathrm{mol}$ respectively. Also, at the inhibitor binding site of $3 \mathrm{CL}^{\text {pro }}, 2-0-\mathrm{Caffeoyl}-(+)$-allohydroxycitric acid exhibited the highest docking score of $-5.6 \mathrm{kcal} / \mathrm{mol}$ against binding to $3 \mathrm{CL}^{\text {pro }}$ in comparison to the other studied compounds. Therefore from the molecular docking, the results indicate that Geraniin and 2-0-Caffeoyl-(+)allohydroxycitric acid bind favourably to their respective targets when compared to other phytochemicals and could thus eventually modulate the activities of their target enzymes for therapeutic purposes upon further investigations.

\subsubsection{Exploring the binding mechanisms of identified hit bioactive phytochemicals against SARS-CoV-2 therapeutic targets}

The mechanism of binding of inhibitors to biological targets is influenced by the nature of the interactions engaged between the inhibitor and binding site amino acid residues. These interactions consequentially influence the conformational stability and binding affinity of inhibitors towards their targets. 
Therefore, inhibitor-residue interactions are very crucial in the overall therapeutic potential of inhibitors. Using the Discovery Studio[121], we visualized and explored the residue interaction profile of both Geraniin and 2-0Caffeoyl-(+)-allohydroxycitric acid upon binding to SARS-CoV-2 3CL ${ }^{\text {pro }}$, SARS-CoV-2 RdRp, and the RBD of viral S-protein. This revealed essential atomistic insights that could have informed the favourable binding orientations as observed in the molecular docking simulation.

\subsubsection{SARS-CoV-2 RNA 3 C-like Main Protease-2-0-Caffeoyl-(+)-allohydroxycitric acid complex}

After exhibiting the highest docking towards SARS-CoV-2 $3 \mathrm{CL}^{\text {pro }}$ amongst all the investigated compounds as shown in Table 2, we further explored the possible binding mechanisms of 2-0-Caffeoyl-(+)-allohydroxycitric acid by analysing its interaction profile with binding site residues. As shown in Figure 3 an exploration of the binding interactions of 2-0-Caffeoyl-(+)-allohydroxycitric acid towards $3 \mathrm{CL}^{\text {pro }}$ revealed the formation of strong intermolecular interactions with crucial binding site residues. Notably, strong conventional hydrogen bond interactions were formed with Csy145, Asn142 and His163. Cys145 is also shown to engage in an additional pi-cation interaction with the bound inhibitor emphasizing its cruciality to the binding of 2-0Caffeoyl-(+)-allohydroxycitric acid. A study by Hall et al,(2020)[122] reported that His163 is essential to the inhibition of $3 \mathrm{CL}^{\text {pro }}$ since the mutation of its homologous residue His 162 in SARS protease inactivates $3 \mathrm{CL}^{\text {pro}}[122]$. As such, the conventional hydrogen bond interaction exhibited between 2-0-Caffeoyl-(+)allohydroxycitric acid and His 163 confirms the cruciality of this residue and also predicts a possible inhibitory potential of 2-0-Caffeoyl-(+)-allohydroxycitric acid against $3 \mathrm{CL}^{\text {pro }}$. Also, 2-0-Caffeoyl-(+)allohydroxycitric acid is shown to elicit a conventional hydrogen bond interaction with Cys145, one of the catalytic dyad (Cys145 and His41)[123] of $3 \mathrm{CL}^{\text {pro }}$ further suggesting its possible inhibitory activity against $3 \mathrm{CL}^{\text {pro }}$. These strong interactions observed could have contributed to the favourable binding orientation of 2-O-Caffeoyl-(+)-allohydroxycitric acid and its consequential high docking score as calculated in the molecular docking process. Considering previous in vitro reports on the antiviral activity of 2-0-Caffeoyl-(+)allohydroxycitric acid against Coxsackie and Herpes simplex viruses[49], the molecular insights provided in this report about its possible activity against SARS-CoV-2 $3 \mathrm{CL}^{\text {pro }}$ warrant its further experimental validations.

\subsubsection{SARS-CoV-2 RNA Dependent RNA Polymerase-Geraniin complexes}

As shown in Figure 2, Geraniin, which exhibited the highest docking score amongst the studied phytochemicals against SARS-CoV-2 RdRp is bonded within the binding pocket by a pi-alkyl interaction with Arg550, a conventional hydrogen bond with both Arg555 and Ala553 while a pi-cation interaction is engaged with Arg836. In addition, Geraniin is also shown to elicit conventional hydrogen bond interactions with Asn691, Asn760, and Asp623 while a carbon-hydrogen bond interaction was formed with Lys621 in deeper regions of the inhibitor binding site. These interactions could have accounted for its favourable docking orientation within the SARS-CoV-2 RdRp inhibitor binding pocket relative to the other phytochemical compounds as established in the molecular docking simulation. A comparison of the docking score of Geraniin $(-10.4 \mathrm{kcal} / \mathrm{mol})$ with that of the docking score of Remdesivir $(-5.9 \mathrm{kcal} / \mathrm{mol})[124]$, within the same grid box dimensions, revealed that Geraniin showed a relatively higher docking score than Remdemsivir. This relatively higher docking score of Geraniin, in addition to its strong intermolecular interactions engaged with 
binding pocket residues of SARS-CoV-2 RdRp conforms with a possible inhibitory activity. In addition to its previously antiviral activity[80, 82], these revealed atomistic binding insights against SARS-CoV-2 RdRp suggests that Geraniin could be further investigated as a possible inhibitor against SARS-CoV-2.

\subsubsection{SARS-CoV-2 Receptor Binding Domain-Geraniin complexes}

As shown in table 2 Geraniin also exhibited the highest docking score toward the RBD of SARS-CoV-2 viral Sprotein. By examining its residue interaction profile with the RBD, we explored its possible binding mechanism. A successful blockage of the RBD of viral S-protein by Geranin could prevent the binding of RBD of viral S-protein and SARS-CoV-2. As shown in Figure 3, Geraniin is engaged in a wide network of interactions, notably, conventional hydrogen bond interactions were formed with Arg403, Tyr495, Tyr453, Ser494, GIn493, Gln498 and Tyr505 while a carbon-hydrogen interaction is observed with Gln498. These strong conventional hydrogen interactions could anchor Geraniin within the binding pocket to ensure its stability for favourable binding and consequential interruption of the activity of RBD of the viral S-protein. The interacting residues were also consistent with prominent residues reported by several studies in which novel SARS-CoV-2 inhibitors have been predicting thus further establishing the potential inhibitory prowess of Geraniin[125].In addition to the previously reported antiviral activity of Geraniin[80,82], the atomistic and structural insights provided in this study warrants further exploration of Geraniin as a possible binder of the receptor-binding domain of viral S-protein towards COVID-19 therapy.

\subsubsection{Identified Hits exhibit favorable binding free energy towards SARS-CoV-2 3CL ${ }^{\text {pro }}$, RdRp and RBD of viral Sprotein}

Inhibitor stability within the binding pocket is very crucial in determining biological processes with consequential pharmaceutical implications. Therefore, to establish the stability of the identified hits within the respective SARS-CoV-2 target, we assessed their binding free energy over the simulation period using the MMPB-SA approach since binding affinities from molecular docking are inconclusive. The MMPB-SA calculations also allowed for a quantitative determination of absolute binding affinities of the identified hits[126]. The calculated binding free energies allow for a thorough understanding of the mechanism by which the respective SARS-CoV-2 targets recognizes the identified hits which in turn influences the inhibitory potential of the hits against those targets[127]. Favourable binding free energies of hit compounds indicate stability within the pocket which could in turn favour binding site interactions[126]. As shown in table 3 the binding free energy of Geraniin towards RdRp and RBD of viral S protein was calculated to be $-25.87 \mathrm{kcal} / \mathrm{mol}$ and $-21.74 \mathrm{kcal} / \mathrm{mol}$ respectively while the binding free energy of 2-0-Caffeoyl-(+)-

allohydroxycitric acid was estimated as $-32.00 \mathrm{kcal} / \mathrm{mol}$. Overall, all three compounds bound exhibited strong binding affinity towards their respective target corroborating with the strong interaction bonds elicited binding pockets as revealed in the interaction dynamics. 2-0-Caffeoyl-(+)-allohydroxycitric acid exhibited almost similar binding free energy with Ritonavir which exhibited a total binding free energy of $-32.34 \mathrm{kcal} / \mathrm{mol}$. Also, a comparison of the binding free energy of Geraniin to the known SARS-CoV-2 RdRp inhibitor, Remdesivir, showed that Geraniin exhibited a relatively lower binding free energy with Remdesivir demonstrating binding free energy of $-33.34 \mathrm{kcal} / \mathrm{mol}$. This further highlighted the therapeutic potential of these hits and hence warrants their further experimental investigations. 
Table 3. MM/PBSA-based binding free energy profile of identified hit compounds against respective SARS-CoV-2 therapeutic targets

\begin{tabular}{|c|c|c|c|c|c|}
\hline Complexes & $\begin{array}{l}\text { Energy comp } \\
\text { (kcal/mol) }\end{array}$ & nents & & & \\
\hline $2 O C A-3 C L^{p r o}$ & $-32.06 \pm 0.16$ & $-55.91 \pm 0.58$ & $-87.97 \pm 0.67$ & $55.12 \pm 0.39$ & $-32.00 \pm 0.31$ \\
\hline $\begin{array}{l}\text { Ritonavir- } \\
\text { 3CLPro }\end{array}$ & $-49.71 \pm 0.33$ & $-40.35 \pm 0.65$ & $-9.35 \pm 0.84$ & $\begin{array}{l}-22.99 \\
\pm 0.59\end{array}$ & $\begin{array}{l}-32.34 \\
\pm 0.34\end{array}$ \\
\hline $\begin{array}{l}\text { Geraniin- } \\
R B D\end{array}$ & $-36.22 \pm 0.23$ & $-23.12 \pm 0.49$ & $-59.34 \pm 0.66$ & $37.60 \pm 0.42$ & $-21.74 \pm 0.27$ \\
\hline $\begin{array}{l}\text { Geraniin- } \\
\text { RdRp }\end{array}$ & $-24.00 \pm 0.84$ & $-49.28 \pm 1.74$ & $-73.29 \pm 2.57$ & $47.41 \pm 1.67$ & $-25.87 \pm 0.91$ \\
\hline $\begin{array}{l}\text { Remdemsivir- } \\
\text { RdRp }\end{array}$ & $-44.4 \pm 0.3$ & $-38.7 \pm 0.8$ & $-83.2 \pm 1.0$ & $49.5 \pm 0.7$ & $-33.4 \pm 0.4$ \\
\hline
\end{tabular}
$\Delta \mathrm{E}_{\text {ele }}=$ electrostatic energy; $\Delta \mathrm{E}_{\mathrm{vdW}}=$ van der Waals energy; $\Delta \mathrm{G}_{\mathrm{bind}}=$ total binding free energy; $\Delta G_{\text {sol }}=$ solvation free energy $\Delta G_{\text {gas }}=$ gas phase free energy.

\subsubsection{Assessing the structural and conformational changes of SARS-CoV-2 therapeutic targets upon binding of Geraniin and 2-0-Caffeoyl-(+)-allohydroxycitric acid}

As a reliable and widely employed computational technique, molecular dynamics simulations were used to conduct a time-dependent prediction of the structural and conformational motions that occur on the SARSCoV-2 therapeutic targets upon the binding of the identified bioactive compounds [128-130]. Any observed structural changes on these enzymes could provide essential conformational insights that could contribute to the potential inhibitory activity of the compounds. MD simulations also allowed for an assessment of the conformational stability of the targets upon binding of the compounds since these could provide valuable insights into the potential inhibitory prowess of the compounds. Also, since molecular docking calculations were done using the rigid X-ray crystal structures of the target SARS-CoV-2 enzymes, MD simulation allowed for an assessment of target receptor and corresponding bound inhibitor interactions in the dynamic behaviour of both the enzymes and the identified bioactive compounds. With an adequate 200ns MD simulation period, we calculated the root mean square deviation (RMSD)[131] and root mean square fluctuation (RMSF) $[130,132]$ to assess conformational stability and residue flexibility. The structural and conformational alterations that were unraveled suggest a possible inhibitory mechanism of the identified antiviral phytochemical compounds since these changes could interfere with enzyme functions.

\subsubsection{2-0-Caffeoyl-(+)-allohydroxycitric acid-binding perturbs $3 \mathrm{CL}^{\text {pro }}$}


Several recent reports have investigated the conformational dynamics of unliganded of SARS-CoV$23 \mathrm{CL}^{\text {pro }}$ including a recent molecular dynamics simulations study by Suarez and Diaz, (2020)[133] where they revealed that the domain III of $3 \mathrm{CL}^{\text {pro }}$ is generally unstable while the presence of peptide substrate, AceAla-Val-Leu-GIn Ser-Nme, induces a stable interdomain arrangement in the monomeric conformation of the protease. These conformational changes of enzymes are the hallmarks of their dynamics that correlate with the overall functions of these enzymes[133]. Therefore, when induced by potential inhibitors, these conformational changes could interfere with their known functions. By calculating the RMSD of the Ca atoms of $3 \mathrm{CL}^{\text {pro }}$ over the $200 \mathrm{~ns}$ simulation period, the impact of the binding of 2-0-Caffeoyl-(+)allohydroxycitric acid on the stability of $3 \mathrm{CL}^{\text {pro }}$ was assessed. The stability of an enzyme structure is crucial in the maintenance of its function [134]. As shown in the Figure $4 A$ and $4 B$, both unbound and bound simulated models of $3 \mathrm{CL}^{\text {pro }}$ converged around $75 \mathrm{~ns}$ after an initial jump in deviation due to the expansion of atoms. On average, the unbound conformation of $3 \mathrm{CL}^{\text {pro }}$ exhibited a relatively higher RMSD of $2.53 \AA$ while the inhibitor bound conformation exhibited a lower RMSD of $2.43 \AA$. This suggested that the binding mechanism of 2-0-Caffeoyl-(+)-allohydroxycitric acid involved a consequential increase in the stability of $3 \mathrm{CL}^{\text {pro }}$ consistent with the earlier reports by Suarez and Natalia in which substrate binding was shown to induce a stable interdomain conformation. The stabilized conformation of $3 \mathrm{CL}^{\text {pro }}$ upon the binding of 2-0Caffeoyl-(+)-allohydroxycitric acid could further facilitate a favorable interaction with crucial active site residues to impede the functions of $3 \mathrm{CL}^{\text {pro }}$. Root Mean Square Fluctuation (RMSF) which provided atomistic insights on the flexibility of each of the 306 amino acid residues of $3 \mathrm{CL}^{\text {pro }}$ was estimated as presented in figure 4. Comparatively, the unbound simulated model of $3 \mathrm{CL}^{\text {pro }}$ exhibited an average RMSF of $9.90 \AA$ while the 2-O-Caffeoyl-(+)-allohydroxycitric acid bound model showed a relatively lower average RMSF of 9.16 This suggested that the binding of 2-0-Caffeoyl-(+)-allohydroxycitric acid impeded the flexibility of individual amino acids of $3 \mathrm{CL}^{\text {pro }}$, consistent with the relatively lower average RMSD of the bound conformation as observed. This impeded residue flexibility could intend to interfere with the essential residue mobility required for the function of $3 \mathrm{CL}^{\text {pro }}$. From the RMSF and RMSD calculations, it could therefore be inferred that the binding of 2-0-Caffeoyl-(+)-allohydroxycitric acid is characterised by a stabilized structural conformation and an impeded residue flexibility which in turn interfere with essential enzyme mobility.

\subsubsection{Geraniin binding distorts conformational integrity of SARS-CoV-2 RdRP}

A recent comparative molecular dynamics simulations study by Koulgi et al (2020) in which the unbound and Remdesivir-complexed structures of SARS-CoV-2 RdRp showed the blocking of the template entry site upon Remdesivir binding[135]. Their report further revealed that Remdesivir binding is characterised by structural instability and increased residue flexibility. Therefore, to ascertain the inhibitory potential of Geraniin against RdRp, we also assessed the conformational dynamics of RdRp upon Geraniin binding. In a similar mechanism as Remdesivir, the binding of Geraniin also increased the deviation of c-a atoms of RdRp consistent with structural instability. As shown in Figure 5A, a relatively higher average RMSD of 3.08 calculated for the Geraniin bound RdRp while the unbound RdRp exhibited an average RMSD of $2.5 \AA$. Likewise, as shown in Figure 5B the binding of Geraniin also induced prominent residue fluctuations as was reported for Remdesivir binding in the study by Koulgi et al.,(2020)[135]. An average RMSF of 32.01A was estimated for the Geraniin bound RdRp while an average RMSF of $21.70 \AA$ was calculated for the unbound 
conformation. Taken together, it could be inferred that the binding of Geraniin distorts the structural integrity of SARS-CoV-2 RdRp in a similar mechanism as Remdesivir. As such, Geraniin could further be investigated as a potential inhibitor of SARS-CoV-2 RdRp.

\subsubsection{Geraniin binding influence the receptor accessibility or inaccessibility of the spike protein}

According to a recent report by Gur et al, (2019) [136], the down and up positions of SARS-CoV-2 RBD can interfere with the accessibility of the spike protein by controlling its open (receptor accessible) and closed (receptor inaccessible) positions. Therefore, it is evident that any conformational changes of RBD induced by a bound inhibitor could influence any intended therapeutic inhibition. A calculation of the RMSD of the simulated RBD models as presented in Figures $6 \mathrm{~A}$ and $6 \mathrm{~B}$ revealed that the unbound conformation of RBD showcased an average RMSD of $7.20 \AA$ while the Geraniin bound RBD showed an average RMSD of $10.17 \AA$. The significantly higher average RMSD of the bound conformation suggests that the binding of Geraniin possibly increased the deviation of $\mathrm{c}$-a atoms and hence subsequently decreased the conformational stability of RBD. The flexibility of the individual amino acids of RBD was also accessed to unravel any conformational changes on RBD upon Geraniin binding. As shown in Figure 6, an average RMSF of $12.96 \AA$ and $13.08 \AA$ was calculated for the unbound and inhibitor bound conformation of RBD respectively. Although the difference in average residue fluctuations between the bound and unbound conformations was minimal, the relatively higher average RMSF in the Geraniin bound structure confers with increased residue flexibility suggesting that the binding of Geraniin distorted the residue integrity of RBD which subsequently increased the residue motions as observed. This increased residue mobility of RBD upon Geraniin binding could in turn favour a down and up motion of RBD and hence possibly influence the receptor accessibility or inaccessibility of the spike protein as postulated by Gur et al,(2019) [136].

\subsection{Assessing the pharmacokinetic properties of Geraniin and 2-0-Caffeoyl-(+)-allohydroxycitric acid}

The physicochemical and pharmacokinetic features of drugs are very crucial to their overall therapeutic success. As such, we analysed the physicochemical and pharmacokinetic properties of Geraniin and 2-0Caffeoyl-(+)-allohydroxycitric acid using the online platform SwissADME[105]. An in silico assessment of these properties, notably absorption, distribution, metabolism, and excretion offers insights into the pharmacokinetics of a given small molecular inhibitor in vivo while minimizing the risk of being disapproved during late stages of drug development $[137,138]$. As shown in table 4 , the properties as assessed from SwissADME are presented[105]. Since natural products are usually not compatible with Lipinski's Rule of 5 [106-108], rules propounded from relatively simple small molecules, it suggests Geraniin and 2-0-Caffeoyl-(+)-allohydroxycitric acid warrant further experimental investigation for their potential antiSARS-CoV-2 properties. Using the Brain Or IntestinaL EstimateD permeation method (BOILED-Egg) concept[139], the SwissADME platform was also used to predict the lipophilicity (log P) and polarity of Geraniin and 2-O-Caffeoyl-(+)-allohydroxycitric acid compound[140, 141]. By calculating the LogP of the compounds, we predicted their permeability across cellular membranes. According to Lipinski's rule of five, the Log P of a compound intended for oral administration should not be more than 5[142]. As such, higher $\log \mathrm{P}$ is usually associated with a compound with minimal potential of permeating the lipid membrane. With a $\log \mathrm{P}$ of -1.71 and -0.65 for Geraniin and 2-0-Caffeoyl-(+)-allohydroxycitric acid respectively, it suggests both compounds will exhibit high membrane permeability, hence a possibly high bioavailability and 
absorption. An assessment of the molecular weights (MW) of both compounds was found to be $952.64 \mathrm{~g} / \mathrm{mol}$ and $379.27 \mathrm{~g} / \mathrm{mol}$ for Geraniin and 2-0-Caffeoyl-(+)-allohydroxycitric acid. The relatively lower MW of 2-0-Caffeoyl-(+)-allohydroxycitric acid $(<500 \mathrm{~g} / \mathrm{mol})$, suggests that it could possess minimal toxicity tendencies[143]. Although Geraniin has a large MW of $952.64 \mathrm{~g} / \mathrm{mol}$, its synthetic fragmentation into smaller simpler compounds could increase its bioactivity and decrease toxicity[144].

Table 4: Pharmacokinetic properties of Geraniin, and 2-O-Caffeoyl-(+)-allohydroxycitric acid

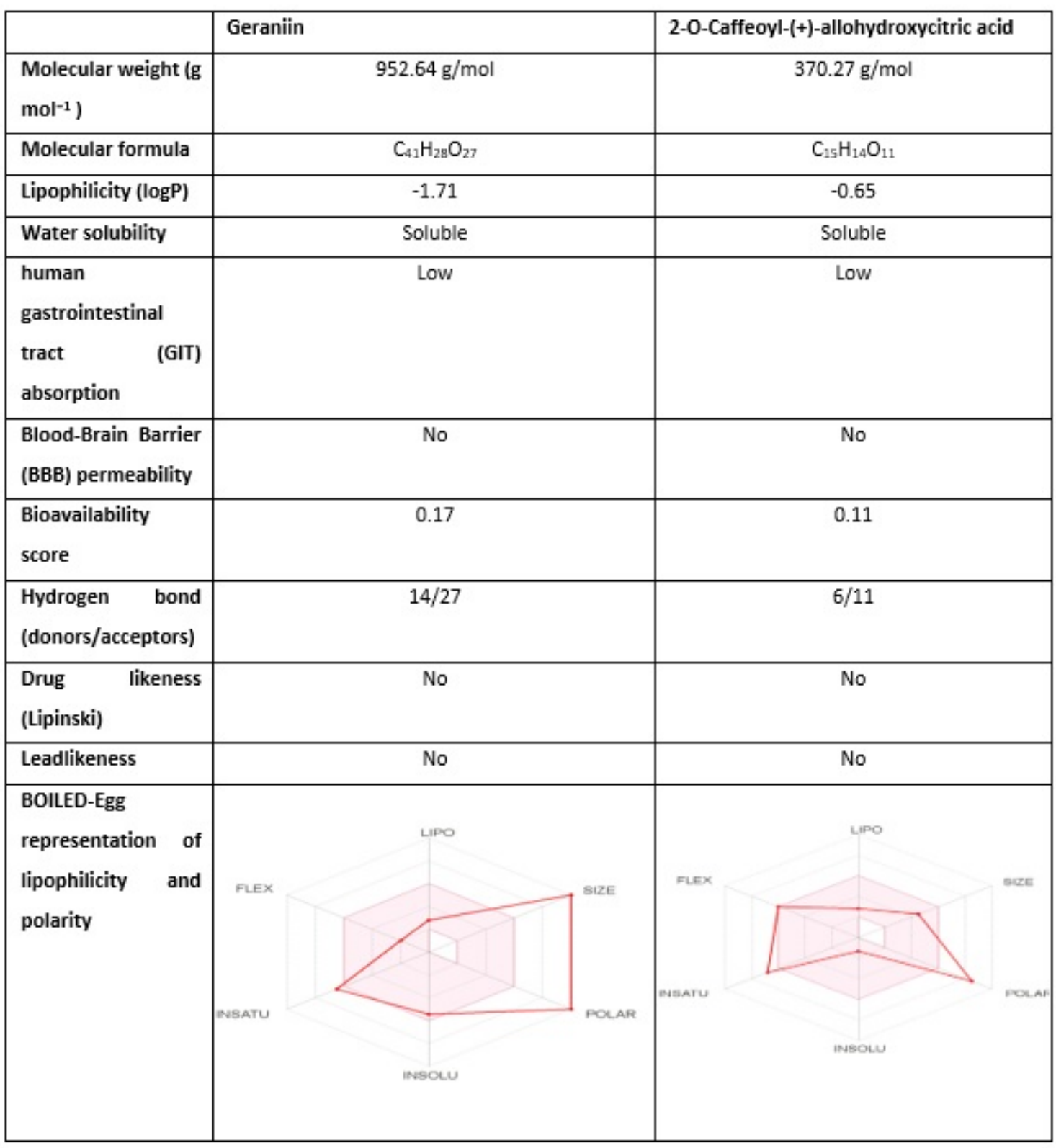

\subsection{Conclusion}

This in silico study identified two bioactive compounds; Geraniin and 2-0-Caffeoyl-(+)-allohydroxycitric acid as potential repurposing therapeutic inhibitors against SARS-CoV-2. Using Molecular Mechanics/PoissonBoltzmann Surface Area (MMPB-SA) approach to calculate binding free energy, Geraniin exhibited binding free energy $\left(\Delta G_{\text {bind }}\right)$ of $-25.87 \mathrm{kcal} / \mathrm{mol}$ and $-21.74 \mathrm{kcal} / \mathrm{mol}$ respectively towards SARS-CoV-2 RdRp and RBD 
of viral S protein respectively. 2-0-Caffeoyl-(+)-allohydroxycitric acid on the other hand exhibited a

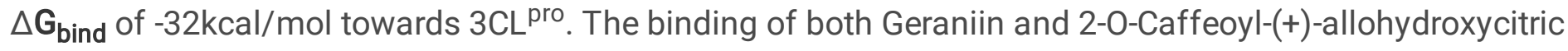
acid were characterised strong interactions with respective SARS-CoV-2 therapeutic target suggesting an inhibitory potential and their ability to bind favourably to SARS-CoV-2 RNA-dependent polymerase, 3CL ${ }^{\text {pro }}$ and RBD of the viral S-protein. Molecular Dynamics (MD) simulations further revealed crucial structural changes induced Geraniin and 2-0-Caffeoyl-(+)-allohydroxycitric acid which possibly interfered with enzyme functions. Notable structural changes included, increased residue flexibility of and a distortion of the structural integrity of SARS-CoV-2 RdRp RBD upon Geraniin binding. The binding of 2-O-Caffeoyl-(+)allohydroxycitric acid also stabilized the structural conformation and impeded residue flexibility of $3 \mathrm{CL}^{\text {pro }}$. The molecular insights provided with regards to the inhibitory potency of the two phytochemicals warrant an extensive experimental evaluation towards the discovery of novel SARS-CoV-2 therapeutics. To the best of our knowledge, this is the first time Geraniin and 2-0-Caffeoyl-(+)-allohydroxycitric acid have been reported as potential repurposing SARS-CoV-2 inhibitors.

\section{Declarations}

\section{Conflict of interest}

The authors declare no conflicts of interest.

\section{Funding}

No funding was obtained.

\section{Code Availability}

Not applicable

\section{Authors' contributions}

A. Boadu conceived, performed and drafted the paper. C Agoni performed MD simulation and performed a supervisory role. M. Nlooto, R. Kaarpoormath and M. Soliman played supervisory roles. The opinions and views expressed in this manuscript are that of the authors.

\section{Future perspective/ Implications of results}

To the best of our knowledge, this is the first account of in silico study aimed at phytochemical compounds; Geraniin and 2-0-Caffeoyl-(+)-allohydroxycitric acid isolated from ethanolic leaf extract of S. mombin, against SARS-CoV-2 RNA-dependent polymerase, 3CLpro, and receptor binding domain of viral S-protein.

It is therefore envisaged that interest will be generated for in vitro study of the inhibitory potency of the crude ethanolic extract of $S$. mombin and/or pure compounds of Geraniin and 2-0-Caffeoyl-(+)-allohydroxycitric acid towards the discovery of novel SARS-CoV-2 therapeutics. 


\section{References}

1. Li, X., et al., Human Coronaviruses: General Features. Reference Module in Biomedical Sciences, 2019.

2. Modrow, S., et al., Viruses: Definition, Structure, Classification. Molecular Virology, 2020: p. 17.

3. Peng, X., et al., Transmission routes of 2019-nCoV and controls in dental practice. International Journal of Oral Science, 2020. 12(1): p. 1-6.

4. Tellier, R., et al., Recognition of aerosol transmission of infectious agents: a commentary. BMC infectious diseases, 2019. 19(1): p. 101.

5. Chu, H., et al., Comparative replication and immune activation profiles of SARS-CoV-2 and SARS-CoV in human lungs: an ex vivo study with implications for the pathogenesis of COVID-19. Clinical Infectious Diseases, 2020.

6. Wang, S., et al., Coronaviruses and the Associated Potential Therapeutics for the Viral Infections. Journal of Infectious Diseases and Therapy, 2020. 8(2).

7. Lai, C.-C., et al., Severe acute respiratory syndrome coronavirus 2 (SARS-CoV-2) and corona virus disease-2019 (COVID-19): the epidemic and the challenges. International journal of antimicrobial agents, 2020: p. 105924.

8. Chan-Yeung, M. and R. Xu, SARS: epidemiology. Respirology 8 Supp/ S9-14. 2003.

9. Hanege, F.M., et al., SARS-CoV-2 Presence in the Saliva, Tears, and Cerumen of COVID-19 Patients. The Laryngoscope, 2021. 131(5): p. E1677-E1682.

10. Patel, K.P., et al., Transmission of SARS-CoV-2: an update of current literature. European Journal of Clinical Microbiology \& Infectious Diseases, 2020: p. 1-7.

11. Kwon, T., N.N. Gaudreault, and J.A. Richt, Seasonal stability of SARS-CoV-2 in biological fluids. Pathogens, 2021. 10(5): p. 540.

12. Karia, R., et al., COVID-19 and its Modes of Transmission. SN comprehensive clinical medicine, 2020: p. 1-4.

13. Furuya, H., Prediction of Potential Respiratory Tract Infection from SARS-CoV-2 Through Hand-toface Contact Transmission. Tokai J Exp Clin Med, 2020. 45(4): p. 170-175.

14. Masotti, F., et al., Transmission routes, preventive measures and control strategies of SARS-CoV-2 in the food factory. Critical Reviews in Food Science and Nutrition, 2021: p. 1-12.

15. Brazell, L.R., et al., Environmental Screening for Surface SARS-CoV-2 Contamination in Urban HighTouch Areas. medRxiv, 2021. 
16. Kraay, A.N., et al., Risk for Fomite-Mediated Transmission of SARS-CoV-2 in Child Daycares, Schools, Nursing Homes, and Offices. Emerging infectious diseases, 2021. 27(4): p. 1229.

17. Zhou, P., et al., ZHANG w. Si Hr, zHu y, li B, HuanG cl, cHen HD, cHen J, luo y, Guo H, JianG rD, liu MQ, cHen y, SHen Xr, WanG X, zHenG XS, zHao K, cHen QJ, DenG F, liu II, yan B, zHan FX, WanG yy, Xiao GF, SHi zl. A pneumonia outbreak associated with a new coronavirus of probable bat origin. Nature, 2020. 579: p. 270273.

18. Li, Y., et al., A Comprehensive Review of the Global Efforts on COVID-19 Vaccine Development. ACS Central Science, 2021. 7(4): p. 512-533.

19. Li, Q. and H. Lu, Latest updates on COVID-19 vaccines. BioScience Trends, 2020.

20. Carvalho, J.C., et al., Hypersensitivity Reactions to Vaccines: Current Evidence and Standards for SARS-CoV-2 Vaccines. Acta Médica Portuguesa, 2021. 34(13).

21. Burgess, L.H., et al., COVID-19: The Vaccine Race Continues. HCA Healthcare Journal of Medicine, 2021. 2(2): p. 2.

22. Savarino, A., et al., Effects of chloroquine on viral infections: an old drug against today's diseases. The Lancet infectious diseases, 2003. 3(11): p. 722-727.

23. Dan, Z., D. Sheng-Ming, and T. Qiang, COVID-19: a recommendation to examine the effect of hydroxychloroquine in preventing infection and progression/ Journal of Antimicrobial Chemotherapy. J Antimicrob Chemother, 2020: p. 1-4.

24. Colson, P., J.-M. Rolain, and D. Raoult, Chloroquine for the 2019 novel coronavirus SARS-CoV-2. International journal of antimicrobial agents, 2020. 55(3): p. 105923.

25. Barlow, A., et al., Review of emerging pharmacotherapy for the treatment of coronavirus disease 2019. Pharmacotherapy: The Journal of Human Pharmacology and Drug Therapy, 2020. 40(5): p. 416-437.

26. Dong, L., S. Hu, and J. Gao, Discovering drugs to treat coronavirus disease 2019 (COVID-19). Drug discoveries \& therapeutics, 2020. 14(1): p. 58-60.

27. Wang, M., et al., Remdesivir and chloroquine effectively inhibit the recently emerged novel coronavirus (2019-nCoV) in vitro. Cell research, 2020. 30(3): p. 269-271.

28. Awadasseid, A., et al., Effective drugs used to combat SARS-CoV-2 infection and the current status of vaccines. Biomedicine \& Pharmacotherapy, 2021: p. 111330.

29. Lamb, Y.N., Remdesivir: first approval. Drugs, 2020: p. 1-9.

30. Malin, J.J., et al., Remdesivir against COVID-19 and other viral diseases. Clinical microbiology reviews, 2021. 34(1). 
31. Aleissa, M.M., et al., New perspectives on antimicrobial agents: remdesivir treatment for COVID-19. Antimicrobial agents and chemotherapy, 2021. 65(1).

32. Choy, K.-T., et al., Remdesivir, lopinavir, emetine, and homoharringtonine inhibit SARS-CoV-2 replication in vitro. Antiviral research, 2020. 178: p. 104786.

33. Tu, Y.-F., et al., A review of SARS-CoV-2 and the ongoing clinical trials. International journal of molecular sciences, 2020. 21(7): p. 2657.

34. Chakraborty, S., et al., SARS-CoV-2 vaccines in advanced clinical trials: Where do we stand. Advanced Drug Delivery Reviews, 2021.

35. Pandey, A., et al., Potential therapeutic targets for combating SARS-CoV-2: Drug repurposing, clinical trials and recent advancements. Life sciences, 2020: p. 117883.

36. Molavi, Z., et al., Identification of FDA approved drugs against SARS-CoV-2 RNA dependent RNA polymerase (RdRp) and 3-chymotrypsin-like protease (3CLpro), drug repurposing approach. Biomedicine \& Pharmacotherapy, 2021: p. 111544.

37. Gul, S., et al., In silico identification of widely used and well-tolerated drugs as potential SARS-CoV-2 $3 C$-like protease and viral RNA-dependent RNA polymerase inhibitors for direct use in clinical trials. Journal of Biomolecular Structure and Dynamics, 2020: p. 1-20.

38. Udofia, I.A., et al., In silico studies of selected multi-drug targeting against 3CLpro and nsp12 RNAdependent RNA-polymerase proteins of SARS-CoV-2 and SARS-CoV. Network Modeling Analysis in Health Informatics and Bioinformatics, 2021. 10(1): p. 1-12.

39. Basu, A., A. Sarkar, and U. Maulik, Computational approach for the design of potential spike protein binding natural compounds in SARS-CoV2. 2020.

40. Oyewole, 0.0.0., USE HERBS TO COMBAT COVID-19 INFECTION.

41. Elendran, S., et al., The physicochemical properties of geraniin, a potential antihyperglycemic agent. Pharmaceutical biology, 2015. 53(12): p. 1719-1726.

42. Huang, F., et al., A review of therapeutic agents and Chinese herbal medicines against SARS-COV-2 (COVID-19). Pharmacological Research, 2020: p. 104929.

43. Osuntokun, O.T., Synergistic efficacy of Aframomum melegueta [Roscoe] K. Schum and Spondias mombin (Linn), A predictive treatment of SARS-CoV-2 (COVID-19) Infection.

44. Khaerunnisa, S., et al., Potential inhibitor of COVID-19 main protease (Mpro) from several medicinal plant compounds by molecular docking study. Prepr. doi10, 2020. 20944: p. 1-14.

45. Falang, K.D., et al., Combinatorial Evaluation of Antiviral Activity of some Nigerian Medicinal Plants on SARS-CoV-2Combinatorial Evaluation of Antiviral Activity of some Nigerian Medicinal Plants on SARS- 
CoV-2. Journal of Complementary and Alternative Medical Research, 2020: p. 38-50.

46. Salman, S., et al., Virtual screening of immunomodulatory medicinal compounds as promising antiSARS-COV-2 inhibitors. Future Virology, 2020(0).

47. Duvall, C.S., On the origin of the tree Spondias mombin in Africa. Journal of Historical Geography, 2006. 32(2): p. 249-266.

48. Silva, A., et al., Antiviral activities of extracts and phenolic components of two Spondias species against dengue virus. Journal of Venomous Animals and Toxins Including Tropical Diseases, 2011. 17(4): p. 406-413.

49. Corthout, J., et al., Antiviral caffeoyl esters from Spondias mombin. Phytochemistry, 1992. 31(6): p. 1979-1981.

50. Corthout, J., et al., Antiviral ellagitannins from Spondias mombin. Phytochemistry, 1991. 30(4): p. 1129-1130.

51. de Pinto, G.L., et al., Structural investigation of the polysaccharide of Spondias mombin gum. Carbohydrate polymers, 2000. 43(2): p. 105-112.

52. Nworu, C.S., et al., The leaf extract of Spondias mombin L. displays an anti-inflammatory effect and suppresses inducible formation of tumor necrosis factor-a and nitric oxide (NO). Journal of immunotoxicology, 2011. 8(1): p. 10-16.

53. Sasidharan, S., et al., Extraction, isolation and characterization of bioactive compounds from plants' extracts. African Journal of Traditional, Complementary and Alternative Medicines, 2011. 8(1).

54. Akram, M., et al., Antiviral potential of medicinal plants against HIV, HSV, influenza, hepatitis, and coxsackievirus: A systematic review. Phytotherapy Research, 2018. 32(5): p. 811-822.

55. Ben-Shabat, S., et al., Antiviral effect of phytochemicals from medicinal plants: applications and drug delivery strategies. Drug Delivery and Translational Research, 2020: p. 1-14.

56. Adams, M., F. Gmünder, and M. Hamburger, Plants traditionally used in age related brain disordersa survey of ethnobotanical literature. Journal of Ethnopharmacology, 2007. 113(3): p. 363-381.

57. Adedokun, M., et al., Socio-economic importance and utilization of Spondias mombin in Nigeria. Asian Pacific Journal of Tropical Medicine, 2010. 3(3): p. 232-234.

58. Hermans, M., A. Akoègninou, and J. van der Maesen, Medicinal plants used to treat malaria in southern Benin. Economic Botany, 2004. 58(1): p. S239-S252.

59. Idowu, O., et al., Ethnobotanical survey of antimalarial plants used in Ogun State, Southwest Nigeria. African Journal of Pharmacy and Pharmacology, 2010. 4(2): p. 055-060. 
60. Iyamah, P. and M. Idu, Ethnomedicinal survey of plants used in the treatment of malaria in Southern Nigeria. Journal of ethnopharmacology, 2015. 173: p. 287-302.

61. Traore, M., et al., Ethnobotanical survey on medicinal plants used by Guinean traditional healers in the treatment of malaria. Journal of ethnopharmacology, 2013. 150(3): p. 1145-1153.

62. Fred-Jaiyesimi, A., A. Kio, and W. Richard, a-Amylase inhibitory effect of 3 $\beta$-olean-12-en-3-yl (9Z)hexadec-9-enoate isolated from Spondias mombin leaf. Food Chemistry, 2009. 116(1): p. 285-288.

63. Gbolade, A. and A. Adeyemi, Anthelmintic activities of three medicinal plants from Nigeria. Fitoterapia, 2008. 79(3): p. 223-225.

64. Ogbole, O. and E. Ajaiyeoba, Traditional management of tuberculosis in Ogun State of Nigeria: the practice and ethnobotanical survey. African Journal of Traditional, Complementary and Alternative Medicines, 2010. 7(1).

65. Erhabor, J., M. Idu, and F. Udo, Ethnomedicinal survey of medicinal plants used in the treatment of male infertilty among the IFA Nkari People of Ini Local Government area of Akwa Ibom State, Nigeria. Research Journal of Recent Sciences ISSN,

2013. 2277: p. 2502.

66. Awogbindin, l., et al., Assessment of flavonoid content, free radical scavenging and hepatoprotective activities of Ocimum gratissimum and Spondias mombin in rats treated with dimethylnitrosamine. Arch Bas Appl Med, 2014. 2(1): p. 45-54.

67. Ishola, I.O., B.O. Ikuomola, and 0.0. Adeyemi, Protective role of Spondias mombin leaf and Cola acuminata seed extracts against scopolamineinduced cognitive dysfunction. Alexandria Journal of Medicine, 2018. 54(1): p. 27-39.

68. Sabiu, S., et al., Indomethacin-induced gastric ulceration in rats: protective roles of Spondias mombin and Ficus exasperata. Toxicology reports, 2015. 2: p. 261-267.

69. Abad, M., et al., Antiinflammatory activity of some medicinal plant extracts from Venezuela. Journal of Ethnopharmacology, 1996. 55(1): p. 63-68.

70. Oladunmoye, M., Comparative evaluation of the effects of leaf extract from Spondias mombin on rats with induced infections from Bacillus cereus and Clostridium sporogenes. Research Journal of Phytochemistry, 2010. 4(4): p. 264-269.

71. Igwe, C., et al., Evaluation of the chemical compositions of the leaf of Spondias mombin Linn from Nigeria. Australian Journal of Basic and Applied Sciences, 2010. 4(5): p. 706-710.

72. Maduka, H., et al., Phytochemical, antioxidant and microbial inhibitory effects of Spondias mombin leaf and stem bark extracts. J Pharm Biol Sci, 2014. 9(2): p. 14-17. 
73. Njoku, P. and M. Akumefula, Phytochemical and nutrient evaluation of Spondias mombin leaves. Pak. J. Nutr, 2007. 6(6): p. 613-615.

74. Cheng, H.S., S.H. Ton, and K.A. Kadir, Ellagitannin geraniin: a review of the natural sources, biosynthesis, pharmacokinetics and biological effects. Phytochemistry reviews, 2017. 16(1): p. 159-193.

75. Perera, A., S.H. Ton, and U.D. Palanisamy, Perspectives on geraniin, a multifunctional natural bioactive compound. Trends in Food Science \& Technology, 2015. 44(2): p. 243-257.

76. Choi, J.-G., et al., Antiviral activity of ethanol extract of Geranii Herba and its components against influenza viruses via neuraminidase inhibition. Scientific reports, 2019. 9(1): p. 1-12.

77. Liu, C., et al., Identification of hydrolyzable tannins (punicalagin, punicalin and geraniin) as novel inhibitors of hepatitis B virus covalently closed circular DNA. Antiviral research, 2016. 134: p. 97-107.

78. Yang, C.-M., et al., The in vitro activity of geraniin and 1, 3, 4, 6-tetra-O-galloyl- $\beta$-d-glucose isolated from Phyllanthus urinaria against herpes simplex virus type 1 and type 2 infection. Journal of ethnopharmacology, 2007. 110(3): p. 555-558.

79. Yang, Y., et al., Antiviral effect of geraniin on human enterovirus 71 in vitro and in vivo. Bioorganic \& medicinal chemistry letters, 2012. 22(6): p. 2209-2211.

80. Li, J., et al., Anti-hepatitis B virus activities of Geranium carolinianum L. extracts and identification of the active components. Biological and Pharmaceutical Bulletin, 2008. 31(4): p. 743-747.

81. Siqueira, E.M.d.S., et al., Antiviral Potential of Spondias mombin L. Leaves Extract Against Herpes Simplex Virus Type-1 Replication Using In Vitro and In Silico Approaches. Planta Medica, 2020. 86(07): p. 505-515.

82. Ahmad, S.A.A., et al., Efficacy of geraniin on dengue virus type-2 infected BALB/c mice. Virology journal, 2019. 16(1): p. 26.

83. Haddad, J.G., et al., The Geraniin-Rich Extract from Reunion Island Endemic Medicinal Plant Phyllanthus phillyreifolius Inhibits Zika and Dengue Virus Infection at Non-Toxic Effect Doses in Zebrafish. Molecules, 2020. 25(10): p. 2316.

84. Ahmad, S.A.A., et al., Geraniin extracted from the rind of Nephelium lappaceum binds to dengue virus type-2 envelope protein and inhibits early stage of virus replication. Virology journal, 2017. 14(1): p. 113.

85. Mahmood, N., et al., Constituents of Cuscuto reflexa are anti-HIV Agents. Antiviral chemistry and chemotherapy, 1997. 8(1): p. 70-74.

86. Leaf-nosed bat, in Encyclopædia Britannica. 2009, Encyclopædia Britannica Online. 
87. Wu, C., et al., Analysis of therapeutic targets for SARS-CoV-2 and discovery of potential drugs by computational methods. Acta Pharmaceutica Sinica B, 2020.

88. Kirchdoerfer, R.N. and A.B. Ward, Structure of the SARS-CoV nsp12 polymerase bound to nsp7 and nsp8 co-factors. Nature communications, 2019. 10(1): p. 1-9.

89. Subissi, L., et al., SARS-CoV ORF1b-encoded nonstructural proteins 12-16: replicative enzymes as antiviral targets. Antiviral research, 2014. 101: p. 122-130.

90. Imbert, I., et al., A second, non-canonical RNA-dependent RNA polymerase in SARS Coronavirus. The EMBO journal, 2006. 25(20): p. 4933-4942.

91. Chu, C.K., et al., Antiviral activity of nucleoside analogues against SARS-coronavirus (SARS-CoV). Antiviral Chemistry and Chemotherapy, 2006. 17(5): p. 285-289.

92. Wan, Y., et al., Receptor recognition by the novel coronavirus from Wuhan: an analysis based on decade-long structural studies of SARS coronavirus. Journal of virology, 2020. 94(7).

93. Anand, K., et al., Coronavirus main proteinase (3CLpro) structure: basis for design of anti-SARS drugs. Science, 2003. 300(5626): p. 1763-1767.

94. Mesecar, A., A taxonomically-driven approach to development of potent, broad-spectrum inhibitors of coronavirus main protease including SARS-CoV-2 (COVID-19). Be Publ, 2020.

95. Yang, H., et al., The crystal structures of severe acute respiratory syndrome virus main protease and its complex with an inhibitor. Proceedings of the National Academy of Sciences, 2003. 100(23): p. 1319013195.

96. Bacha, U., et al., Identification of novel inhibitors of the SARS coronavirus main protease 3CLpro. Biochemistry, 2004. 43(17): p. 4906-4912.

97. Berman, H.M., et al., The protein data bank. Acta Crystallographica Section D: Biological Crystallography, 2002. 58(6): p. 899-907.

98. Gao, Y., et al., Structure of the RNA-dependent RNA polymerase from COVID-19 virus. Science, 2020. 368(6492): p. 779-782.

99. Liu, X., et al., The crytal structure of 2019-nCoV main protease in complex with an inhibitor N3. RCSB Protein Data Bank, 2020.

100. Yan, R., et al., Structural basis for the recognition of the 2019-nCoV by human ACE2. BioRxiv, 2020.

101. Pettersen, E.F., et al., UCSF Chimera-a visualization system for exploratory research and analysis. Journal of computational chemistry, 2004. 25(13): p. 1605-1612.

102. ChemAxon, L., Marvinsketch. 2013, ChemAxon Cambridge. 
103. Hanwell, M.D., et al., Avogadro: an advanced semantic chemical editor, visualization, and analysis platform. Journal of cheminformatics, 2012. 4(1): p. 17.

104. Trott, O. and A.J. Olson, AutoDock Vina: improving the speed and accuracy of docking with a new scoring function, efficient optimization, and multithreading. Journal of computational chemistry, 2010. 31(2): p. $455-461$.

105. Daina, A., O. Michielin, and V. Zoete, SwissADME: a free web tool to evaluate pharmacokinetics, drug-likeness and medicinal chemistry friendliness of small molecules. Scientific reports, 2017. 7: p. 42717.

106. Lipinski, C.A., Lipinski's rule of five.

107. Ganesan, A., The impact of natural products upon modern drug discovery. Current opinion in chemical biology, 2008. 12(3): p. 306-317.

108. Ali, A.F.A.I., Is there a Lipinski-analogous set of rules for natural products? 2012.

109. Case, D., et al., Amber 2018: San Francisco. 2018, California.

110. Le Grand, S., A.W. Götz, and R.C. Walker, SPFP: Speed without compromise-A mixed precision model for GPU accelerated molecular dynamics simulations. Computer Physics Communications, 2013. 184(2): p. 374-380.

111. Salomon-Ferrer, R., et al., Routine microsecond molecular dynamics simulations with AMBER on GPUs. 2. Explicit solvent particle mesh Ewald. Journal of chemical theory and computation, 2013. 9(9): p. 3878-3888.

112. Maier, J.A., et al., ff14SB: improving the accuracy of protein side chain and backbone parameters from ff99SB. Journal of chemical theory and computation, 2015. 11(8): p. 3696-3713.

113. Case, D.A., et al., The Amber biomolecular simulation programs. Journal of computational chemistry, 2005. 26(16): p. 1668-1688.

114. Berendsen, H.J., et al., Molecular dynamics with coupling to an external bath. The Journal of chemical physics, 1984. 81(8): p. 3684-3690.

115. Kräutler, V., W.F. Van Gunsteren, and P.H. Hünenberger, $A$ fast SHAKE algorithm to solve distance constraint equations for small molecules in molecular dynamics simulations. Journal of computational chemistry, 2001. 22(5): p. 501-508.

116. Roe, D.R. and T.E. Cheatham III, PTRAJ and CPPTRAJ: software for processing and analysis of molecular dynamics trajectory data. Journal of chemical theory and computation, 2013. 9(7): p. 3084-3095.

117. Seifert, E., OriginPro 9.1: Scientific Data Analysis and Graphing Software囚 Software Review. 2014, ACS Publications. 
118. Wang, C., et al., Recent developments and applications of the MMPBSA method. Frontiers in molecular biosciences, 2018. 4: p. 87.

119. Miller III, B.R., et al., MMPBSA. py: an efficient program for end-state free energy calculations. Journal of chemical theory and computation, 2012. 8(9): p. 3314-3321.

120. Du, X., et al., Insights into protein-ligand interactions: mechanisms, models, and methods. International journal of molecular sciences, 2016. 17(2): p. 144.

121. Jejurikar, B.L. and S.H. Rohane, Drug Designing in Discovery Studio. Asian Journal of Research in Chemistry, 2021. 14(2): p. 135-138.

122. Hall Jr, D.C. and H.-F. Ji, A search for medications to treat COVID-19 via in silico molecular docking models of the SARS-CoV-2 spike glycoprotein and $3 \mathrm{CL}$ protease. Travel medicine and infectious disease, 2020: p. 101646.

123. ul Qamar, M.T., et al., Structural basis of SARS-CoV-2 3CLpro and anti-COVID-19 drug discovery from medicinal plants. Journal of pharmaceutical analysis, 2020.

124. Wang, M., R. Cao, and L. Zhang, Remdesivir and chloroquine effectively inhibit the recently emerged novel coronavirus (2019 nCoV) in vitro [published online February 4, 2020]. Cell Res. doi. 10.

125. Muhseen, Z.T., et al., Promising terpenes as SARS-CoV-2 spike receptor-binding domain (RBD) attachment inhibitors to the human ACE2 receptor: integrated computational approach. Journal of molecular liquids, 2020. 320: p. 114493.

126. Raha, K. and K.M. Merz Jr, Calculating binding free energy in protein-ligand interaction. Annual reports in computational chemistry, 2005. 1: p. 113-130.

127. Wlodawer, A., Rational approach to AIDS drug design through structural biology. Annual review of medicine, 2002. 53(1): p. 595-614.

128. Salmaso, V. and S. Moro, Bridging molecular docking to molecular dynamics in exploring ligandprotein recognition process: An overview. Frontiers in pharmacology, 2018. 9: p. 923.

129. Durrant, J.D. and J.A. McCammon, Molecular dynamics simulations and drug discovery. BMC biology, 2011. 9(1): p. 1-9.

130. Karshikoff, A., L. Nilsson, and R. Ladenstein, Rigidity versus flexibility: the dilemma of understanding protein thermal stability. The FEBS journal, 2015. 282(20): p. 3899-3917.

131. Pitera, J.W., Expected distributions of root-mean-square positional deviations in proteins. The Journal of Physical Chemistry B, 2014. 118(24): p. 6526-6530.

132. Bornot, A., C. Etchebest, and A.G. De Brevern, Predicting protein flexibility through the prediction of local structures. Proteins: Structure, Function, and Bioinformatics, 2011. 79(3): p. 839-852. 
133. Suárez, D. and N. Díaz, SARS-CoV-2 Main Protease: A Molecular Dynamic Study. 2020.

134. Pace, C.N., et al., Forces contributing to the conformational stability of proteins. The FASEB journal, 1996. 10(1): p. 75-83.

135. Koulgi, S., et al., Remdesivir-bound and ligand-free simulations reveal the probable mechanism of inhibiting the RNA dependent RNA polymerase of severe acute respiratory syndrome coronavirus 2. RSC Advances, 2020. 10(45): p. 26792-26803.

136. Gur, M., et al., Exploring Conformational Transition of 2019 Novel Coronavirus Spike Glycoprotein Between Its Closed and Open States Using Molecular Dynamics Simulations. bioRxiv, 2020.

137. Geerts, T. and Y. Vander Heyden, In silico predictions of ADME-Tox properties: drug absorption. Combinatorial chemistry \& high throughput screening, 2011. 14(5): p. 339-361.

138. Kalita, J.M., et al., ADVANCES IN COMPUTER AIDED DRUG DESIGN. Universal J of Pharm Sci Res, 2015. 1: p. 17-22.

139. Daina, A., O. Michielin, and V. Zoete, SwissADME: a free web tool to evaluate pharmacokinetics, drug-likeness and medicinal chemistry friendliness of small molecules. Scientific reports, 2017. 7(1): p. 1-13.

140. Péronnet, F., et al., Pharmacokinetic analysis of absorption, distribution and disappearance of ingested water labeled with D 20 in humans. European journal of applied physiology, 2012. 112(6): p. 22132222.

141. Daina, A. and V. Zoete, A boiled-egg to predict gastrointestinal absorption and brain penetration of small molecules. ChemMedChem, 2016. 11(11): p. 1117.

142. Lipinski, C.A., et al., Experimental and computational approaches to estimate solubility and permeability in drug discovery and development settings. Advanced drug delivery reviews, 1997. 23(1-3): p. 325.

143. Struck, S., et al., Toxicity versus potency: elucidation of toxicity properties discriminating between toxins, drugs, and natural compounds, in Genome Informatics 2008: Genome Informatics Series Vol. 20. 2008, World Scientific. p. 231-242.

144. Olotu, F.A., G. Munsamy, and M.E. Soliman, Does Size Really Matter? Probing the Efficacy of Structural Reduction in the Optimization of Bioderived Compounds-A Computational "Proof-of-Concept". Computational and Structural Biotechnology Journal, 2018. 16: p. 573-586.

\section{Figures}




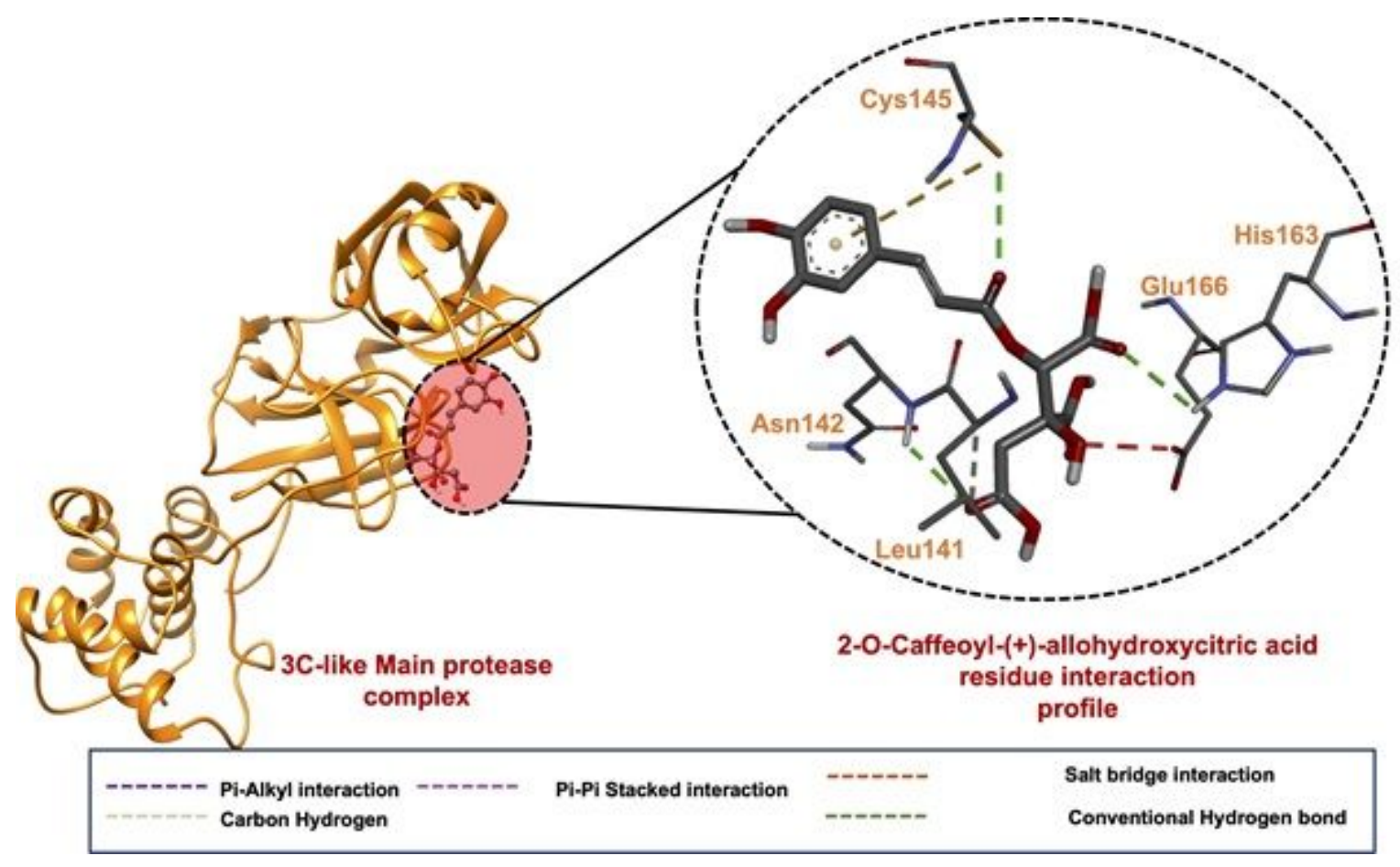

Figure 1

A) A 3D complex of 3CLpro- 2-0-Caffeoyl-(+)-allohydroxycitric acid. B) A 3D ligand interaction plot of the RdRp-2-0-Caffeoyl-(+)-allohydroxycitric acid complex.

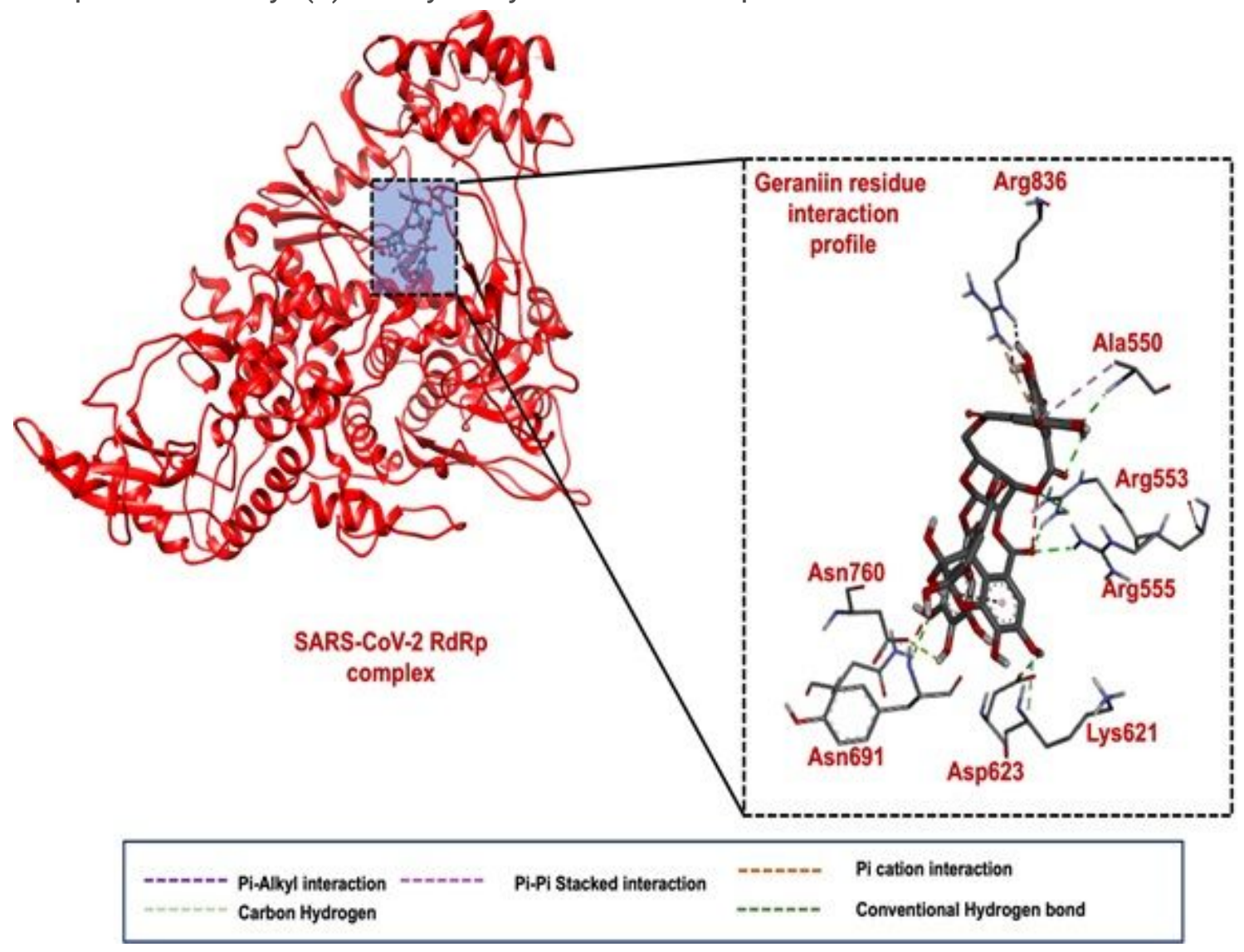

Figure 2 
A) 3D representation of RdRp bound with Geraniin B) 3D ligand interaction plot of the RdRp bound with Geraniin.

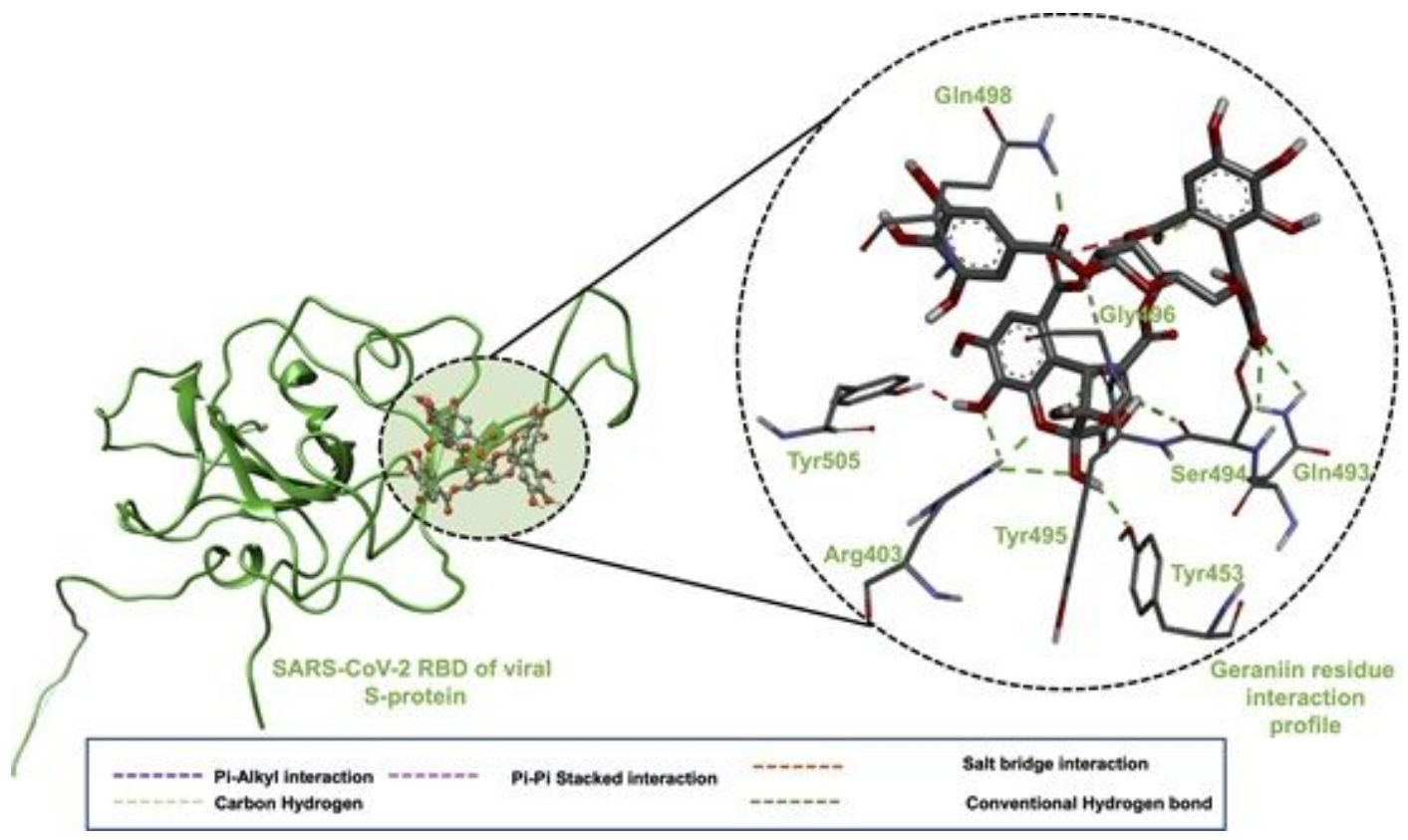

\section{Figure 3}

A) 3D complex of RBD of viral S-protein and Geraniin B) 3D ligand interaction plot of the RBD of viral Sprotein complexed with Geraniin

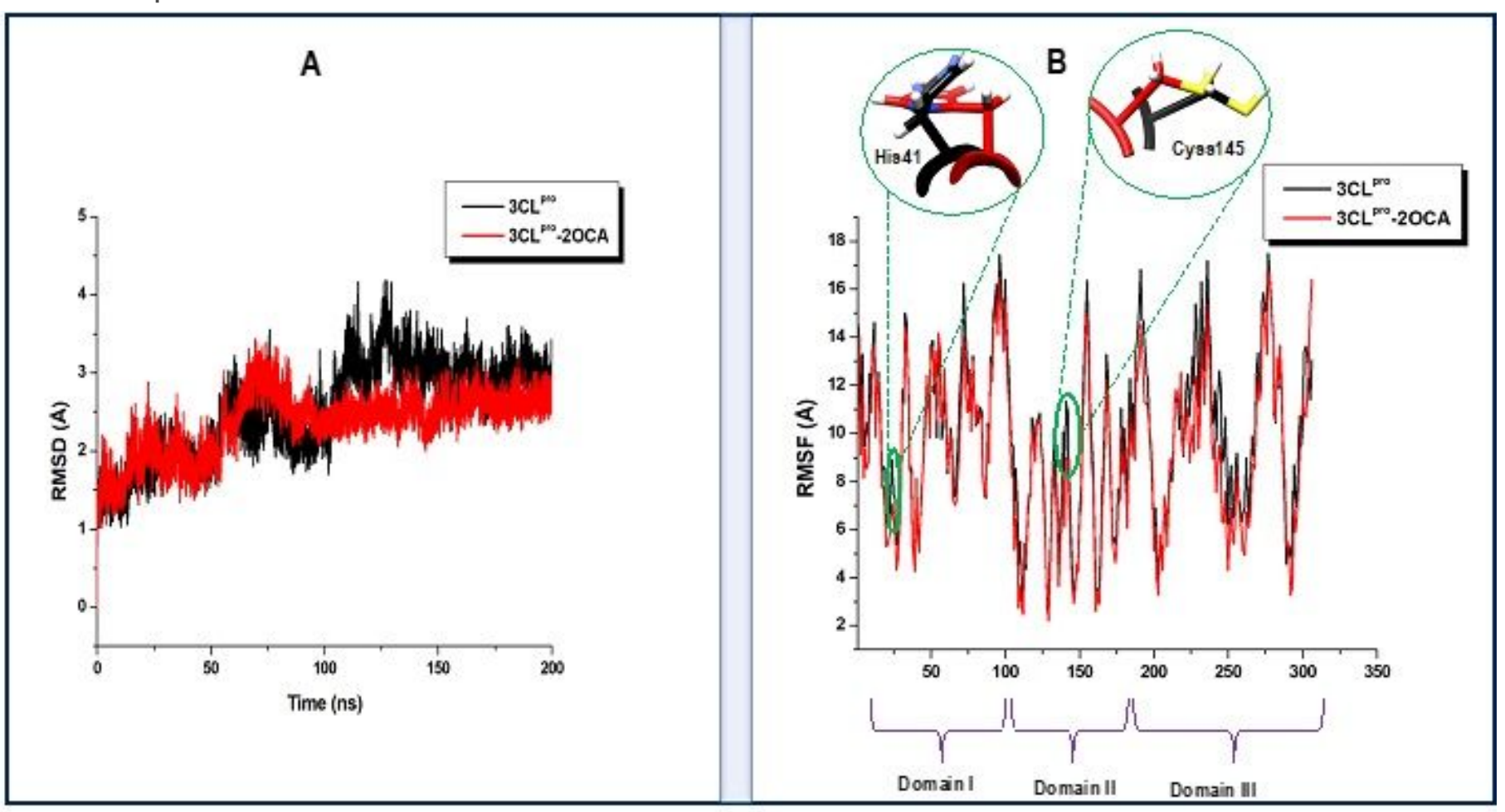

Figure 4

A) Comparative root mean square deviation plots of the 2-0-Caffeoyl-(+)-allohydroxycitric acid bound (red) and unbound (black) 3CLpro. showing that inhibitor stabilized the 3CLpro. B) Comparative root mean square 
fluctuation plots of the 2-0-Caffeoyl-(+)-allohydroxycitric acid bound (red) and unbound (black) 3CLpro. Insert highlights 3D representation of the variation in flexibility of the catalytic dyad of 3CLpro in both bound and unbound conformations

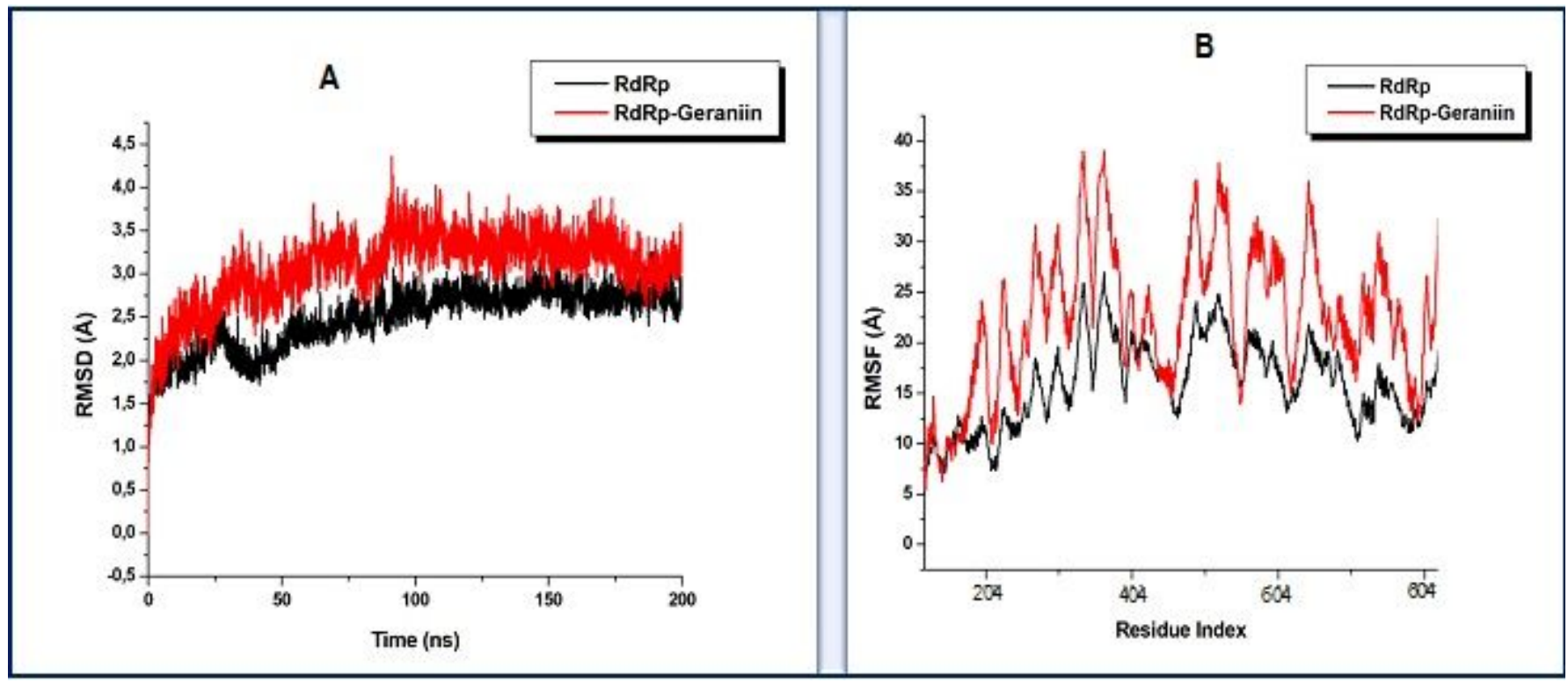

\section{Figure 5}

A) Comparative root mean square deviation plots of the Geraniin bound (red) and unbound (black) RdRp. showing that Geraniin induced an unstable conformation in RdRp. B) Comparative root mean square fluctuation plots of the Geraniin bound (red) and unbound (black) RdRp showing increased residue flexibility upon Geraniin binding.

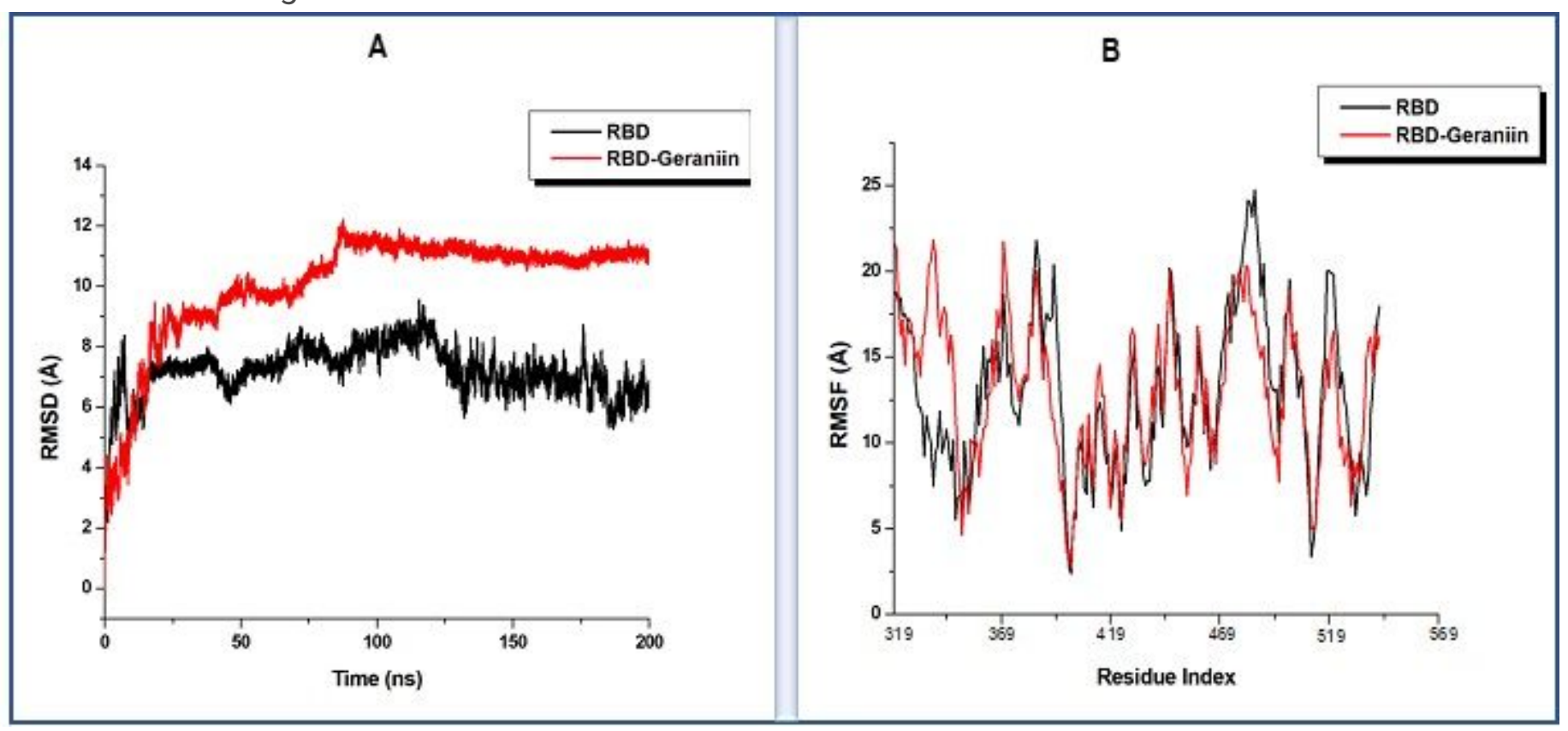

\section{Figure 6}

A) Comparative root mean square deviation plots of the Geraniin bound (red) and unbound (black) RBD, showing that Geraniin induced an unstable conformation in RBD. B) Comparative root mean square 
fluctuation plots of the Geraniin bound (red) and unbound (black) RBD showing increased residue flexibility upon Geraniin binding. 